\title{
Air pollution, weather, and associated risk factors related to asthma prevalence and attack rate
}

\author{
Wen-Chao Ho ${ }^{\mathrm{a}, \mathrm{b}, *}$, William R. Hartley ${ }^{\mathrm{b}}$, Leann Myers ${ }^{\mathrm{c}}$, Meng-Hung Lin ${ }^{\mathrm{a}}$, Yu-Sheng Lin ${ }^{\mathrm{d}}$, \\ Chih-Hui Lien ${ }^{a}$, Ruey-Shiung Lin ${ }^{\mathrm{e}}$ \\ ${ }^{a}$ Graduate Institute of Environmental Medicine, China Medical University, 91 Hsueh-Shih Road, Taichung, Taiwan 40402, ROC \\ ${ }^{\mathrm{b}}$ Department of Environmental Health Sciences, Tulane University, 1440 Canal Street, Suite 2100, New Orleans, LA 70112, USA \\ ${ }^{\mathrm{c}}$ Department of Biostatistics, Tulane University, 1440 Canal Street, Room 2031, New Orleans, LA 70112, USA \\ ${ }^{\mathrm{d}}$ Department of Environmental and Occupational Health, University of North Texas, Health Science Center, Fort Worth, TX 76107, USA \\ ${ }^{\mathrm{e}}$ Institute of Preventive Medicine, National Taiwan University, 5Fl. No. 17, Hsu Chow Road, Taipei, Taiwan 100, ROC
}

Received 14 August 2006; received in revised form 29 December 2006; accepted 17 January 2007

Available online 21 February 2007

\begin{abstract}
Asthma is an important public health challenge. The objective of this research was to investigate the relationship of air pollution and weather to adolescent asthma prevalence and attack rate. A 6-month mass screening asthma study was conducted from October 1995 to March 1996 in Taiwan. The study population included junior high school students from throughout the country (1,139,452 students). Eighty-nine percent of students completed questionnaires (International Study of Asthma and Allergies in Childhood-ISAAC and New England Core Questionnaires) and passed a logical screening error program. Lung function data was collected to assist in the diagnosis of asthma status. From the students screened during this mass survey, a stratified random sample of 64,660 students was analyzed for asthma prevalence and attack rate. Using a regression model to compare the USEPA National Ambient Air Quality Standards 2000 (NAAQS, 2000) to asthma prevalence, this investigation found that the standards may not provide enough protection for adolescents after controlling for age, rhinitis, eczema, urban birth location, parental education level, exercise, cigarette smoking, environmental tobacco smoking, alcohol beverage consumption and weather factors. The general estimating equations (GEE) model, a repeated measurement regression model, was used to examine the relationship between the monthly asthma attack rate among asthma patients and air pollution (nitrogen oxides; nitrogen dioxide; nitric oxide; Ozone; $\mathrm{PM}_{10}$ ) while controlling for household smoking. The GEE model demonstrated that air pollution is related to asthma attack rate. Air pollution factors also interacted with weather parameters when related to asthma attack rate.
\end{abstract}

(C) 2007 Elsevier Inc. All rights reserved.

Keywords: Air pollution; Weather; Asthma; Prevalence; Attack rate

\section{Introduction}

The objective of this research was to investigate the relationship of air pollution and weather to adolescent asthma prevalence and attack rate after adjusting the effects of notable personal risk factors. In the International Study of Asthma and Allergies in Childhood (ISAAC)

\footnotetext{
${ }^{*}$ Corresponding author. Graduate Institute of Environmental Medicine, China Medical University, 91 Hsueh-Shih Road, Taichung, Taiwan 40402, ROC. Fax: +886422019901.

E-mail address: whocmu@gmail.com (W.-C. Ho).
}

research report, the highest asthma prevalence occurred in industrialized and westernized countries. The highest 12month asthma prevalence rates were in the United Kingdom, New Zealand, Australia, and the Republic of Ireland, followed by North, Central, and South America. The highest adolescent asthma prevalence was $36.8 \%$ in UK (ISAAC Steering Committee, 1998). A community-based epidemiological study of asthma incidence rates in the USA from 1964 to 1983 showed that the rise in asthma incidence was entirely accounted for by the increased incidence rates in the age range of 1-14 years (Yunginger et al., 1992). Hospital admission rates for asthma have also increased 
over time in New Zealand, the United Kingdom and Wales, the United States, Canada, and Australia in the $0-14$ year old age group. The increase was three to ten times over a period of 15 years (1966-1981) (Mitchell, 1985). A series of epidemiological studies of the prevalence of bronchial asthma in schoolchildren using the standardized ISAAC screening methodology was also done in Taipei, Taiwan. The prevalence of childhood asthma increased from $1.30 \%$ in 1974 to $5.04 \%$ in 1985 (Hsieh and Shen, 1988), and continued to rise from $5.80 \%$ in 1991 to $10.79 \%$ in 1994 (Lin et al., 1995).

Air pollution related to asthma was reported worldwide. Traffic-related air pollutants were related to asthma among school children in Taiwan (Guo et al., 1999; Hwang et al., 2005; Wang et al., 1999). Odoriferous chemical vapor related to asthma on fifth graders in Taipei, Taiwan (Tsai et al., 2006). A moderate increase in long-term exposure to background ambient air pollution $\left(\mathrm{SO}_{2}, \mathrm{PM}_{10}\right.$ and $\mathrm{O}_{3}$ were significantly associated with an increased risk of lifetime asthma. Results concerning past year symptoms were consistent, even if not always statistically significant (Penard-Morand et al., 2005). Both $\mathrm{SO}_{2}$ and $\mathrm{O}_{3}$ were associated with increased asthmatic emergency room (ER) visits in Portland (Wilson et al., 2005).

The numbers exposed at levels above National Ambient Air Quality Standard (NAAQS) are on a per million people scale for all the pollutants (American Thoracic Society, 1996). Asthmatics and children are usually considered the highest risk groups for induction of respiratory symptoms and are often targeted for public health studies and interventions.

Weather potentially interacts with air pollution when the relationship between air pollution and asthma is considered. High oxidants, particulate pollution, and low temperatures are related to asthma attack rate in the Los Angeles area (Whittemore and Korn, 1980). Seasonal variation of asthma attack rate is found in New Zealand, Canada, Taiwan and Japan (Bates et al., 1990; Chang et al., 2006; Kanaya, 2001; Kimbell-Dunn et al., 2000).

In May 1995, the Taiwan Environmental Protection Agency (TEPA) was authorized by Taiwanese legislators to collect energy consumption fees to prevent air pollution from causing public health problems. This funding led to the collection of data on air pollution and asthma which were utilized in this study.

\section{Methods}

\subsection{Study subjects}

A 6-month mass screening survey of junior high school students for asthma, including a lung function test, was conducted by TEPA and National Taiwan University (NTU) from October 1995 to March 1996. The students' age distribution was from 10 to 17 years old, and $92 \%$ were 12-15 years old. Stratified cluster random sampling was used to select a sample of junior high school students $(n=69,367)$ for an asthma prevalence analysis from the 1,139,452 students who were surveyed nationwide.

\subsection{Survey and measurement}

Asthma in this study was confirmed by physicians through parental report (New England core questionnaire), video questionnaires administered to children (ISAAC video questionnaire) (Asher et al., 1995), and lung function tests (American Thoracic Society, 1979, 1987). The lung function tests followed the 1979 criteria of the American Thoracic Society (ATS) Snowbird Conference, and the ATS update statement of 1987 (American Thoracic Society, 1979, 1987). Details of the screening survey have been previously reported (Guo et al., 1999; Lin et al., 2001; Wang et al., 1999).

Since 1985, the Taiwan EPA has collected data on air pollution through the Air Quality Monitoring Network (72 air-monitoring stations), which measures pollutants continuously and report hourly, averaging 8766 records per year per station. The parameters measured were $\mathrm{SO}_{2}$ by ultraviolet fluorescence, $\mathrm{CO}$ by ondispersive infrared absorption, $\mathrm{O}_{3}$ by ultraviolet absorption, $\mathrm{PM}_{10}$ by betagauge, $\mathrm{NO}, \mathrm{NO}_{2}$, and $\mathrm{NO}_{x}$ by chemiluminescence (Guo et al., 1999; Hwang et al., 2005). In addition to the data collected on air pollution, the parameters collected for weather included wind, temperature, pressure, rain, and humidity (from Taiwan EPA and Central Weather Bureau).

A five-level scale of exposure was utilized for classification of the level of each pollutant. Level of exposure to an air pollutant was classified as: very high, high, medium, low, and very low for each air pollutant (NO, $\mathrm{NO}_{2}, \mathrm{NO}_{x}, \mathrm{O}_{3}, \mathrm{SO}_{2}, \mathrm{CO}, \mathrm{PM}_{10}$ and PSI). The levels of exposure were included in a logistic stepwise regression analysis. For $\mathrm{NO}_{2}, \mathrm{SO}_{2}$ and $\mathrm{PM}_{10}$, the USEPA NAAQS 1 year average was used to delineate between medium and high levels of exposure. $\mathrm{For}_{3}$ and $\mathrm{CO}$, the USEPA NAAQS $8 \mathrm{~h}$ average was used to define level of exposure as no 1-year average has been developed for these pollutants. Levels of exposure for $\mathrm{NO}$ and $\mathrm{NO}_{x}$ were based on the mean value of concentration distribution since no USEPA standard has been established. Levels of exposure to weather factors were also based on the mean value of concentration distribution because no USEPA standard exists. Each exposure level ranges one standard deviation from the mean concentration distribution. Based upon the Taiwan EPA criteria, 100 PSI (Pollution Standard Index) was used. The range of each exposure level was also based on Taiwan EPA criteria.

\subsection{Data analysis}

Using a logistic regression model for asthma prevalence analysis (binary response-Yes or No), the maximum likelihood estimation was carried out with Fisher's scoring algorithm. The logistic regression procedure was used to specify categorical variables (as class variables) in the model. The stepwise logical regression model was used to select the variables. Selection criteria was $P$-value $=0.05$. A main effect could enter or leave a model in a single step based on the $P$-value score or Wald statistic. Two-way interactions were considered.

The criteria for assessing model fit were Akaike Information Criteria (AIC) and $-2 \log$ Likelihood. AIC was in smaller-is-better form and $-2 \log$ Likelihood was used to test the global null hypothesis (all the parameters associated with covariates were zero).

The general estimating equation (GEE), a repeated measurement model, was used to calculate asthma monthly attack rate among asthma patients while controlling for household smoking. The repeated measurement model specified the covariance structure of multivariate responses for GEE model fitting in the SAS GENMOD procedure. The GENMOD procedure was an extension of traditional linear models. It allowed (1) the mean of a population to depend on a linear predictor through a non-linear link function, and (2) the response probability distribution to be any member of an exponential family of distribution. Monthly asthma attack rate from different asthma patients were assumed to be statistically independent. Monthly attack rates within asthma patients were assumed to be correlated. 


\section{Results}

The demographic comparisons of the stratified sample of students and the overall population were shown on Table 1. The gender ratio and age distribution of the stratified sample of students were similar to the overall population in the mass screening survey (Table 1). The sample also had similar gender and age effects related to asthma prevalence, males had higher asthma prevalence than females, and younger age groups had higher asthma prevalence than older age groups when compared to the overall population. However, the asthma prevalence of the sample among age and gender was lower than the overall population (Table 1). In females, there was an average $0.4 \%$ lower asthma prevalence in stratified sampling than in the overall population among different age groups. In males, there also was an average $0.4 \%$ lower asthma prevalence in the stratified sampling than overall population. However, 12year old students showed a major difference of approximately $1 \%$ for asthma prevalence when compared to the overall population. This difference could potentially exist because of relatively higher asthma prevalence and smaller sample size at age 12 than other age groups.

For females (Table 2), age, quantity of smoking in the household, long-term average temperature lows within the lower $5 \%$ (as measured over 20 years), number of rainy days, $\mathrm{CO}, \mathrm{PM}_{10}$, exercise, smoking, birthplace (city/ county), parents' education, and allergic symptoms (nose and skin) were significant variables. $\mathrm{PM}_{10}$ showed the opposite effect with higher $\mathrm{PM}_{10}$ concentration resulting in less asthma prevalence. However, a higher number of rain days seemed to reduce asthma prevalence; rain days might interact with $\mathrm{PM}_{10}$. Higher long-term average low temperatures was also related to higher asthma prevalence. When $\mathrm{PM}_{10}$ was excluded from the model, rain days was also removed from the model. $\mathrm{PM}_{10}$ might interact with rain days. Although the interaction term was not significant in this stepwise regression model, more complex interaction might exist (more than two-way interaction) after controlling for personal risk factors including allergic symptoms (nose and skin), birthplace (city/county), smoking, exercise, alcohol beverage drinking, parents' education, age, and quantity of cigarette smoking in the household. Females were potentially more sensitive to smoking (first hand and second hand smoking) and weather than males. Considering exercise frequency and asthma for males and females, results suggested that indoor air-pollution had more influence on females than males. $\mathrm{CO}$ was the most consistent air-pollution variable related to increased asthma prevalence. It indicated that traffic related air-pollution might be important in inducing asthma prevalence in Taiwan. $\mathrm{PM}_{10}$ was modified by rain days (washout effect) in inducing asthma.

In males (Table 2), age, $\mathrm{CO}, \mathrm{O}_{3}$, exercise, birthplace (city/county), parent's education, drinking, and allergic symptoms were significant variables in the stepwise model.

Based upon the repeated measurement model, GEE, the air-pollutants and weather factors related to monthly asthma attack rate included: nitrogen oxides; nitrogen dioxide; nitric oxide; ozone; $\mathrm{PM}_{10}$; lowest $5 \%$ monthly

Table 1

Gender-specific, age-specific and gender-age-specific asthma rate of overall population versus subset (from stratified random sampling) in mass screening survey

$\begin{array}{ll}\text { Sampling subset } & \text { Overall population } \\ n_{1} / n_{0}(\%) & N_{1} / N_{0}(\%)\end{array}$

\footnotetext{
Gender specific asthma rate

Females

Males
}

Age specific asthma rate

12

13

14

15

Gender-age specific asthma rate

Female

12

13

14

15

Males

12

13

14

15
$2248 / 34,114(6.6 \%)$

$3385 / 35,254(9.6 \%)$

$1329 / 15,445(8.6 \%)$

$2055 / 23,885(8.6 \%)$

$1763 / 23,364(7.6 \%)$

$458 / 6428(7.1 \%)$
$35,604 / 504,857(7.0 \%)$

$51,225 / 513,061(10.0 \%)$

$22,890 / 243,228(9.4 \%)$

$30,526 / 343,928(8.9 \%)$

$27,151 / 345,568(7.9 \%)$

$5810 / 80,662(7.2 \%)$

$n_{1} / n_{0}$ : asthma rate of subset.

$N_{1} / N_{0}$ : asthma rate of overall population.

${ }^{*} P<0.05$.

$9053 / 120,804(7.5 \%)$

$12,528 / 170,697(7.3 \%)$

$11,342 / 171,572(6.6 \%)$

$2500 / 39,774(6.3 \%)$

$13,837 / 122,424(11.3 \%)$ $17,998 / 173,231(10.4 \%)$ $15,809 / 173,996(9.1 \%)$ $3310 / 40,888(8.1 \%)$ 
Table 2

Asthma prevalence logistic stepwise regression model

\begin{tabular}{|c|c|c|c|c|}
\hline \multirow[t]{2}{*}{ Variable } & \multicolumn{2}{|c|}{ Female $(N=32,012)^{\mathrm{a}}$} & \multicolumn{2}{|c|}{ Male $(N=32,648)^{\mathrm{b}}$} \\
\hline & OR & $95 \% \mathrm{CI}$ & OR & $95 \% \mathrm{CI}$ \\
\hline Age & 0.946 & $0.900-0.994$ & 0.950 & $0.911-0.990$ \\
\hline \multicolumn{5}{|l|}{ Rhinitis } \\
\hline No & 0.238 & $0.217-0.262$ & 0.245 & $0.227-0.265$ \\
\hline Yes & Ref. & - & Ref. & - \\
\hline \multicolumn{5}{|l|}{ Eczema } \\
\hline No & 0.573 & $0.499-0.658$ & 0.611 & $0.543-0.687$ \\
\hline Yes & Ref. & - & Ref. & - \\
\hline \multicolumn{5}{|l|}{ Born in city/county } \\
\hline City & 1.191 & $1.066-1.330$ & 1.116 & $1.016-1.225$ \\
\hline County & Ref. & - & Ref. & - \\
\hline \multicolumn{5}{|l|}{ Parent's education } \\
\hline Primary school & 0.755 & $0.649-0.879$ & 0.724 & $0.639-0.820$ \\
\hline High school & 0.820 & $0.722-0.932$ & 0.789 & $0.710-0.875$ \\
\hline College & Ref. & - & Ref. & - \\
\hline \multicolumn{5}{|l|}{ Exercise } \\
\hline None & 1.186 & $1.037-1.356$ & 1.492 & $1.308-1.703$ \\
\hline Sometime & 0.878 & $0.784-0.982$ & 1.155 & $1.065-1.253$ \\
\hline Often & Ref. & - & Ref. & - \\
\hline \multicolumn{5}{|l|}{ Smoking } \\
\hline No & 0.420 & $0.310-0.568$ & & NS \\
\hline Yes & Ref. & - & Ref. & - \\
\hline \multicolumn{5}{|l|}{ Drinking } \\
\hline No & & NS & 0.540 & $0.448-0.651$ \\
\hline Yes & Ref. & - & Ref. & - \\
\hline ETS (package/day) & 1.080 & $1.001-1.166$ & & NS \\
\hline $\mathrm{CO}$ & 1.984 & $1.536-2.561$ & 1.780 & $1.377-2.302$ \\
\hline $\mathrm{O}_{3}$ & & NS & 1.015 & $1.001-1.029$ \\
\hline $\mathrm{PM}_{10}$ & 0.993 & $0.990-0.997$ & & NS \\
\hline Rain days & 0.998 & $0.996-1.000$ & & NS \\
\hline $\mathrm{TLL}^{\mathrm{c}}$ & 1.114 & $1.056-1.175$ & & NS \\
\hline
\end{tabular}

${ }^{a}$ AIC:intercept only $(15,540)$; intercept and covariates $(14,376)$.

Likelihood Ratio Test: $P<0.0001$.

${ }^{\mathrm{b}}$ AIC:intercept only $(20,518)$; intercept and covariates $(18,847)$.

Likelihood Ratio Test: $P<0.0001$

${ }^{\mathrm{c}}$ Temperature lowest $95 \%$ average (long-term).

Variables including $\mathrm{NO}, \mathrm{NO}_{2}, \mathrm{NO}_{x}, \mathrm{PSI}, \mathrm{SO}_{2}$, Ambient pressure, rain amount, relative humidity, temperature average, temperature highest $95 \%$ average, temperature lowest 95\% average, rain amount (long-term), relative humidity (long-term), temperature average (long-term) and temperature highest $95 \%$ average (long-term) were not significant in both genders.

temperature average; rain amount, and rain days (Table 3). However, sulfur dioxide showed a reversal effect on monthly asthma attack rate. This reversal effect could be caused by the interaction of sulfur dioxide with the lowest $5 \%$ monthly temperature average (Table 4 ).

\section{Discussions and conclusion}

Questionnaire-determined asthma was the outcome in this analysis. In a previous study, Hsieh concluded that the questionnaire was able to differentiate asthmatics from non-asthmatics on the basis of differences in methacholine challenge, intracutaneous skin testing, total eosinophil count, total serum immunoglobulin $\mathrm{E}$ (IgE), and radio-
Table 3

Monthly asthma attack rate vs. single air pollutant concentration and related weather factor (controlling variable: household smoking)

\begin{tabular}{lrr}
\hline Variable & Estimate & $P$-value \\
\hline Nitrogen oxides $\left(\mathrm{NO}_{x}\right)$ & 0.0102 & $<0.0001$ \\
Nitrogen dioxide $\left(\mathrm{NO}_{2}\right)$ & 0.0231 & $<0.0001$ \\
Nitric oxide (NO) & 0.0121 & $<0.0001$ \\
Ozone $\left(\mathrm{O}_{3}\right)$ & 0.0195 & $<0.0001$ \\
$\mathrm{PM}_{10}$ & 0.0050 & $<0.0001$ \\
Carbon monoxide (CO) & 0.0750 & 0.3336 \\
Pollution Standard Index (PSI) & 0.0016 & 0.2549 \\
Sulfur dioxide $\left(\mathrm{SO}_{2}\right)$ & -0.0394 & $<0.0001$ \\
Lowest 5\% monthly temperature average (TL) & -0.0605 & $<0.0001$ \\
Rain amount (RA) & -0.0025 & $<0.0001$ \\
Rain days (RD) & -0.0382 & $<0.0001$ \\
\hline
\end{tabular}

Table 4

Interaction of $\mathrm{SO}_{2}$ and lowest $5 \%$ monthly temperature average (TL)

\begin{tabular}{lrr}
\hline Variable & Estimate & $P$-value \\
\hline Sulfur dioxide $\left(\mathrm{SO}_{2}\right)$ & -0.0193 & 0.3758 \\
Lowest 5\% monthly temperature average (TL) & -0.0527 & $<0.0001$ \\
Interaction term $\left(\mathrm{SO}_{2} \times \mathrm{TL}\right)$ & -0.0010 & 0.3673 \\
\hline
\end{tabular}

Controlling variable: household smoking.

allergosorbent test (RAST) (Hsieh and Shen, 1988; Lin et al., 1995). Questionnaire-determined asthma had a strong correlation with physician-diagnosed asthma. Underestimation of the true asthma morbidity is likely if only parental reports of physician-diagnosed asthma are used (Guo et al., 1999).

Two limitations of exposure assessment in this study are: (1) using monitoring data from existing government stations instead of personal exposure and (2) lack of indoor air data. However, in general, air-monitoring networks can provide a reasonable surrogate measure of exposure for pollutants (Ito et al., 2001). Also, the important factor in relation with indoor and personal exposure to pollutants is the fraction of outdoor air that penetrates indoors. The advantages of this study are in addition to high-density air monitoring stations in Taiwan, heating and air conditioning were not common in both schools and homes until recently. Coal stoves were relatively rare in 1994 (Chen et al., 1998). Furthermore, most of the junior-high school students live close to their schools. The exposure assessment based on ambient air pollution could potentially provide unbiased estimation for both school and home.

One additional potential limitation of this study was that the stratified sampling based on school size may have included more small school students in the sample for analysis. Small schools were more likely to be located in rural areas in Taiwan. Though stratified sampling may have led to higher inclusion of students from small schools, the sampling method may have potentially controlled for different school environments (among different school size) related to asthma prevalence. For example, the sampling 
method may have controlled for group infection and provided more equal sample sizes from urban and rural areas. However, there was slightly lower asthma prevalence in the stratified random sample $(0.4 \%$ less asthma prevalence) than the overall population in mass screening survey; it might reduce urbanization effects related to asthma prevalence. Asthma prevalence for males 12 years of age showed the significant difference of approximately $1 \%$ when compared to the overall population. The higher prevalence of asthma could potentially result from relative higher asthma prevalence and smaller sample size at age 12 than the other age groups. However, the difference in prevalence may be a result of the stratified sampling method utilized to control for urbanization effects. This sampling method may have a greater influence for males who are 12 years old.

Asthma prevalence logistic stepwise regression showed that (1) EPA air-quality criteria might not provide enough protection for the public from asthma; (2) all age groups, quantity of smoking in the household, long-term average temperatures in the lowest $5 \%$, rain days, $\mathrm{CO}, \mathrm{PM}_{10}$, exercise, smoking, birthplace (city/county), parents' education, allergic symptoms (nose and skin) were significant variables in females, and 3) age, $\mathrm{CO}, \mathrm{O}_{3}$, exercise, birthplace (city/county), parent's education, drinking, and allergic symptoms were significant variables in males.

The concentration of air pollutants was related to asthma prevalence based on its own distribution but EPA criteria in the model. It was part of reasons that instead of having air pollution level based on EPA criteria, air pollution concentration (as continuous variable) seemed to fit the model better in asthmatic analyses. Because of the nature of cross-sectional study, the regression model only showed a potentially important association. Further research on cause-effect relationship for protection for the public from asthma is suggested.

Age was significant in the mass screening survey in both genders. Younger age with higher asthma prevalence was found in males aged from 11 to 16, but not in females (Venn et al., 1998). At age 11, asthma prevalence was higher in males than females in both Taiwan and Great Britain (GB). The sex reversal age did not occur until after age 15 in Taiwan (Table 1). It might be because the westernized life style leads to the earlier onset of puberty in GB than in Taiwan. Advanced early onset puberty in females was currently proposed in USA (Kaplowitz and Oberfield, 1999; Lalwani et al., 2003). No such data was reported in Taiwan. General speaking, westernized lifestyle did not start in Taiwan until the fast economic progression during mid-1970s. The westernization lifestyle effects may be earlier and more significant in UK and USA than in Taiwan. Puberty usually starts at an earlier age in females than in males. The age specific asthma prevalence trend in females was more similar to males during age 12-15 might be due to the latter onset puberty in Taiwan. Younger age had higher asthma prevalence in both genders in Taiwan.
Both rhinitis and eczema were significant variables among males and females in the stepwise models. These two illnesses are important atopic disorders that are likely to be associated with asthma through genetic, diet and other environmental factors. Eczema morbidity has an increasing trend similar to that of asthma with a delayed onset by 15 years (Lin et al., 1995). In addition to the fast diet change increased rhinitis and eczema morbidity significantly in eastern German after 2 years of Germany reunification (von Mutius, 1998; von Mutius et al., 1992; von Mutius et al., 1994), the German Multicentre Allery Study (MAS) showed that children with early allergic dermatitis and wheezing was associated with asthma among children at age 7 (Illi et al., 2004). Based in MAS study, the chronic course of continuing allergic airway inflammation beginning in the first 3 years of life was also related to asthma among children at age 13 (Illi et al., 2006).

Asthma is related to early life exposure and is apparently an immune function disorder. Early life exposure is important in inducing asthma. Those who were born in a city had higher asthma prevalence than the people born in county for both genders. The higher urban prevalence may be related to exposure to allergens such dust mite and pollens (Cookson and Moffatt, 1997; Hide et al., 1996; Peat et al., 1990, 1994; Rowntree et al., 1985; Sporik et al., 1990; Van Duren-Schmidt et al., 1997; Zimmerman et al., 1988) and infectious diseases such as measles and respiratory viruses (Coyle et al., 1995; Grunberg et al., 1997; Hussell et al., 1996; Shaheen et al., 1996; Shirakawa et al., 1997; Sigurs et al., 1995; Strachan et al., 1996).

Parents' education is another significant variable in both genders - the higher education parents have, the more likely their child will develop asthma. The possible explanation is that early life exposure was often associated with higher social economic status living and urbanization because of job nature and higher learning stress. It was indicated that stress may be potentially related to asthma and atopic diseases (Kilpelainen et al., 2002; Laube et al., 2002).

Physical activity was potentially associated with weight gain and asthma morbidity (Chinn and Rona, 2001). It was shown to be a significant variable in both genders; more exercise frequency had less asthma prevalence in males. The highest asthma prevalence was observed among females who did not exercise; in contrast, females who have occasional exercise showed lower asthma prevalence than those that exercise frequently.

Smoking and ETS both were significant variables for females. Similar results were found in a partial analysis of two southern Taiwan communities (Wang et al., 1999). ETS was significantly associated with asthma independent of the contribution of other airborne contamination (Radon et al., 2002); in addition, it was probably related to early life exposure (von Mutius, 1998; von Mutius et al., 1992, 1994; Weiss, 1998).

Alcoholic beverage drinking was a significant variable in males, and alcoholic beverage effects could be related to ethanol and non-alcoholic components (Vally and 
Thompson, 2002). In addition, alcoholic beverages may also worsen asthma severity (Cuddy and Li, 2001).

$\mathrm{CO}$, one of the common urban air pollutants, was related to asthma prevalence in both genders. Higher $\mathrm{CO}$ exposure is found to lead to higher asthma prevalence. A similar result was found in partial analyses of mass screening survey (Guo et al., 1999; Wang et al., 1999). CO is related to air pollution produced by traffic. $\mathrm{CO}$ has been suggested to be a neural messenger that causes the inhibition the NO's activity in human body (Ingi et al., 1996). Internal $\mathrm{CO}$ concentration may also interact with external $\mathrm{CO}$ exposure and cause neurological disturbance (Piantadosi, 2002). $\mathrm{PM}_{10}$ showed the reversal effect in increased asthma prevalence in females. Similar results were found in partial mass-screening survey analysis of two south communities (Wang et al., 1999). Rain days reduced asthma prevalence, creating a washout effect; interaction between $\mathrm{PM}_{10}$ and rain days existed. Carbon monoxide was related to increased asthma prevalence in both genders. In the model used to describe the relationship between carbon monoxide and asthma, rain days interacted with $\mathrm{PM}_{10}$. The model also showed traffic-related $\mathbf{P M}_{2.5}$ potentially had a more important role in increased asthma prevalence in Taiwan.

$\mathrm{O}_{3}$ level was proportional to asthma prevalence in males. A similar result was found in partial analysis (Wang et al., 1999). Since it is an important pollutant in photochemical reaction, $\mathrm{O}_{3}$ can stimulate the respiratory tract directly to induce inflammation of the respiratory tract, and to cause toxic response on epidermal cells of respiratory tract (Wardlaw, 1993).

In addition to the "wash-out" effect observed between rain days and $\mathrm{PM}_{10}$ described above, interaction between air pollution and/or allergens exposure to increase asthma prevalence could occur. For example, areas with higher long-term average low temperatures led to higher asthma prevalence in females; females seemed to be more sensitive to weather change than males. It indicates that females growing up with stable temperature are more likely to develop a higher asthma prevalence. Plausible reasons for the relationship between stable temperatures and asthma prevalence include: (1) dust mite and/or fungus exposure; (2) individuals living within stable temperature environments more easily develop asthma when temperatures change, and (3) high geographic altitude has fluctuating temperature but lower asthma prevalence. Temperature changing is also potentially related to respiratory infection. One hypothesis is that respiratory infections in early childhood are related to preventing allergic disease later in life was proposed in the Germany reunion survey (Huttemann, 1999).

From the GEE model, air pollution (nitrogen oxides, nitrogen oxide, nitric oxide, ozone, and $\mathrm{PM}_{10}$ ) was significantly related to asthma attack. Exposure to outdoor air pollutants may be primarily related to exacerbating asthma attack (Etzel, 2003). Weather factors (lowest 5\% temperature average, rain amount, and rain days) were also important in triggering asthma attack. Interaction of air pollution (sulfur dioxide) and weather factor (lowest 5\% temperature average) related to asthma attack was found. PSI is usually used as a mixture index of air pollution, but it was not a significant variable related to asthma attack. It is because when PSI exceeds Taiwan EPA criteria, there is an alarm system to advise asthma patients not to go out. It potentially provides asthma patients a protection from asthma attack in Taiwan. CO was significantly related to asthma prevalence but not asthma attack rate. It might be because a different pathway exists for asthma prevalence and asthma attack rate and/or the lack of relationship between asthma prevalence and asthma attack rate is related to PSI alarm system utilized in Taiwan. After controlling for seasonal effects, air pollution was related to respiratory emergency room visits (Wilson et al., 2005). The interaction of weather and air pollution was found when modeling asthma attack rate (Kanaya, 2001; Venables et al., 1997; Whittemore and Korn, 1980). High oxidant and particulate pollution on cool days were related to the asthma attack rate in the Los Angeles area (Whittemore and Korn, 1980). Thunderstorm and grass pollens were related to asthma the attack rate in the UK as well (Venables et al., 1997). Asian Dust Storms (ADS) were potentially related to asthma attack in Taiwan (Chang et al., 2006). "Fine mist" was also shown to be associated with asthma attack rate in Japan (Kanaya, 2001).

EPA air quality criteria were revised to protect not only the general public but also sensitive groups, like asthmatics. Based on the stepwise regression model, the criteria for single pollutants and mixture (PSI) shows no clear association of protection to prevent asthma prevalence. Reduction of the current levels of ambient air pollution is an important part of the overall effort to minimize asthma morbidity (Wong and Lai, 2004).

Further research is needed. However, the PSI alarm system utilized in Taiwan potentially decreases exposure to air pollution, decreasing asthma attack rate. There was more weather and air pollution interaction in triggering asthma attack among patients. Weather factors need to be considered in asthma prevention strategies.

\section{Acknowledgments}

This research was funded by the Environmental Protection Administration of the Republic of China (Grant No. EPA-85-1404-09-06) and Centers for Disease Control and Prevention-Center for Environmental Health (Grant No. U48/CCU615784) United States of America. We would also like to thank Dr. Sung FC, Dr. Guo YL, Dr. Ko YC, Dr. Lai JS, Dr. Su HJ, Dr. Gou HW, Dr. Shaw CK, Dr. Hsieh KH, Dr. Rabito FA and LaShaunda Malone for their support.

\section{References}

American Thoracic Society, 1979. ATS statement-snowbird workshop on standardization of spirometry. Am. Rev. Respir. Dis. 119, 831-838. 
American Thoracic Society, 1987. Standardization of spirometry-1987 update. Am. Rev. Respir. Dis. 136, 1285-1298.

American Thoracic Society, 1996. Health effects of outdoor air pollution. Am. J. Respir. Crit. Care Med. 153, 3-50.

Asher, M.I., Keil, U., Anderson, H.R., Beasley, R., Crane, J., Martinez, F., et al., 1995. International Study of Asthma and Allergies in Childhood (ISAAC): rationale and methods. Eur. Respir. J. 8, 483-491.

Bates, D.V., Baker-Anderson, M., Sizto, R., 1990. Asthma attack periodicity: a study of hospital emergency visits in Vancouver. Environ. Res. 51, 51-70.

Chang, C.C., Lee, I.M., Tsai, S.S., Yang, C.Y., 2006. Correlation of Asian dust storm events with daily clinic visits for allergic rhinitis in Taipei, Taiwan. J. Toxicol. Environ. Health A 69, 229-235.

Chen, P.C., Lai, Y.M., Wang, J.D., Yang, C.Y., Hwang, J.S., Kuo, H.W., et al., 1998. Adverse effect of air pollution on respiratory health of primary school children in Taiwan. Environ. Health Perspect. 106, 331-335.

Chinn, S., Rona, R.J., 2001. Can the increase in body mass index explain the rising trend in asthma in children? Thorax 56, 845-850.

Cookson, W.O., Moffatt, M.F., 1997. Asthma: an epidemic in the absence of infection? Science 275, 41-42.

Coyle, A.J., Erard, F., Bertrand, C., Walti, S., Pircher, H., Le Gros, G., 1995. Virus-specific CD8 + cells can switch to interleukin 5 production and induce airway eosinophilia. J. Exp. Med. 181, 1229-1233.

Cuddy, R., Li, G., 2001. The role of alcohol in asthma: a review of clinical and experimental studies. Am. J. Emerg. Med. 19, 501-503.

Etzel, R.A., 2003. How environmental exposures influence the development and exacerbation of asthma. Pediatrics 112, 233-239.

Grunberg, K., Timmers, M.C., Smits, H.H., de Klerk, E.P., Dick, E.C., Spaan, W.J., et al., 1997. Effect of experimental rhinovirus 16 colds on airway hyperresponsiveness to histamine and interleukin- 8 in nasal lavage in asthmatic subjects in vivo. Clin. Exp. Allergy 27, 36-45.

Guo, Y.L., Lin, Y.C., Sung, F.C., Huang, S.L., Ko, Y.C., Lai, J.S., et al., 1999. Climate, traffic-related air pollutants, and asthma prevalence in middle-school children in Taiwan. Environ. Health Perspect. 107, 1001-1006.

Hide, D.W., Matthews, S., Tariq, S., Arshad, S.H., 1996. Allergen avoidance in infancy and allergy at 4 years of age. Allergy 51, 89-93.

Hsieh, K.H., Shen, J.J., 1988. Prevalence of childhood asthma in Taipei, Taiwan, and other Asian Pacific countries. J. Asthma 25, 73-82.

Hussell, T., Spender, L.C., Georgiou, A., O'Garra, A., Openshaw, P.J., 1996. Th1 and Th2 cytokine induction in pulmonary T cells during infection with respiratory syncytial virus. J. Gen. Virol. 77 (Part 10), $2447-2455$.

Huttemann, U., 1999. Air pollution and respiratory tract diseases in students. A comparison within Germany. Gesundheitswesen 61, 536-539.

Hwang, B.F., Lee, Y.L., Lin, Y.C., Jaakkola, J.J., Guo, Y.L., 2005. Traffic related air pollution as a determinant of asthma among Taiwanese school children. Thorax 60, 467-473.

Illi, S., von Mutius, E., Lau, S., Nickel, R., Gruber, C., Niggemann, B., et al., 2004. The natural course of atopic dermatitis from birth to age 7 years and the association with asthma. J. Allergy Clin. Immunol. 113, 925-931.

Illi, S., von Mutius, E., Lau, S., Niggemann, B., Gruber, C., Wahn, U., 2006. Perennial allergen sensitisation early in life and chronic asthma in children: a birth cohort study. Lancet 368, 763-770.

Ingi, T., Cheng, J., Ronnett, G.V., 1996. Carbon monoxide: an endogenous modulator of the nitric oxide-cyclic GMP signaling system. Neuron 16, 835-842.

ISAAC Steering Committee, 1998. Worldwide variation in prevalence of symptoms of asthma, allergic rhinoconjunctivitis, and atopic eczema: ISAAC. Lancet 351, 1225-1232.

Ito, K., Thurston, G.D., Nadas, A., Lippmann, M., 2001. Monitor-tomonitor temporal correlation of air pollution and weather variables in the North-Central US. J. Expo. Anal. Environ. Epidemiol. 11, 21-32.
Kanaya, K., 2001. The weather chart pattern inducing asthma attack: the advocacy of "fine mist" as a provocative factor. Arerugi 50, 457-466.

Kaplowitz, P.B., Oberfield, S.E., 1999. Reexamination of the age limit for defining when puberty is precocious in girls in the United States: implications for evaluation and treatment. Drug and Therapeutics and Executive Committees of the Lawson Wilkins Pediatric Endocrine Society. Pediatrics 104, 936-941.

Kilpelainen, M., Koskenvuo, M., Helenius, H., Terho, E.O., 2002. Stressful life events promote the manifestation of asthma and atopic diseases. Clin. Exp. Allergy 32, 256-263.

Kimbell-Dunn, M., Pearce, N., Beasley, R., 2000. Seasonal variation in asthma hospitalizations and death rates in New Zealand. Respirology $5,241-246$.

Lalwani, S., Reindollar, R.H., Davis, A.J., 2003. Normal onset of puberty have definitions of onset changed? Obstet. Gynecol. Clin. North Am. 30, 279-286.

Laube, B.L., Curbow, B.A., Costello, R.W., Fitzgerald, S.T., 2002. A pilot study examining the relationship between stress and serum cortisol concentrations in women with asthma. Respir. Med. 96, 823-828.

Lin, R.S., Sung, F.C., Huang, S.L., Gou, Y.L., Ko, Y.C., Gou, H.W., et al., 2001. Role of urbanization and air pollution in adolescent asthma: a mass screening in Taiwan. J. Formos. Med. Assoc. 100, 649-655.

Lin, R.S., Tai, T.Y., Hsieh, K.H., Luh, K.T., Hsiao, H.C., Lee, L.T., et al., 1995. Asthma Home-care Manual. Taiwan EPA, Taipei.

Mitchell, E.A., 1985. International trends in hospital admission rates for asthma. Arch. Dis. Child. 60, 376-378.

Peat, J.K., Salome, C.M., Woolcock, A.J., 1990. Longitudinal changes in atopy during a 4-year period: relation to bronchial hyperresponsiveness and respiratory symptoms in a population sample of Australian schoolchildren. J. Allergy Clin. Immunol. 85, 65-74.

Peat, J.K., Tovey, E., Gray, E.J., Mellis, C.M., Woolcock, A.J., 1994 Asthma severity and morbidity in a population sample of Sydney schoolchildren: Part II-importance of house dust mite allergens. Aust. NZ J. Med. 24, 270-276.

Penard-Morand, C., Charpin, D., Raherison, C., Kopferschmitt, C., Caillaud, D., Lavaud, F., et al., 2005. Long-term exposure to background air pollution related to respiratory and allergic health in schoolchildren. Clin. Exp. Allergy 35, 1279-1287.

Piantadosi, C.A., 2002. Biological chemistry of carbon monoxide. Antioxid. Redox Signal 4, 259-270.

Radon, K., Busching, K., Heinrich, J., Wichmann, H.E., Jorres, R.A., Magnussen, H., et al., 2002. Passive smoking exposure: a risk factor for chronic bronchitis and asthma in adults? Chest 122, 1086-1090.

Rowntree, S., Cogswell, J.J., Platts-Mills, T.A., Mitchell, E.B., 1985. Development of IgE and IgG antibodies to food and inhalant allergens in children at risk of allergic disease. Arch. Dis. Child 60, 727-735.

Shaheen, S.O., Aaby, P., Hall, A.J., Barker, D.J., Heyes, C.B., Shiell, A.W., et al., 1996. Measles and atopy in Guinea-Bissau. Lancet 347, 1792-1796.

Shirakawa, T., Enomoto, T., Shimazu, S., Hopkin, J.M., 1997. The inverse association between tuberculin responses and atopic disorder. Science 275, 77-79.

Sigurs, N., Bjarnason, R., Sigurbergsson, F., Kjellman, B., Bjorksten, B., 1995. Asthma and immunoglobulin $\mathrm{E}$ antibodies after respiratory syncytial virus bronchiolitis: a prospective cohort study with matched controls. Pediatrics 95, 500-505.

Sporik, R., Holgate, S.T., Platts-Mills, T.A., Cogswell, J.J., 1990. Exposure to house-dust mite allergen (Der p I) and the development of asthma in childhood. A prospective study. N. Engl. J. Med. 323, 502-507.

Strachan, D.P., Butland, B.K., Anderson, H.R., 1996. Incidence and prognosis of asthma and wheezing illness from early childhood to age 33 in a national British cohort. Br. Med. J. 312, 1195-1199.

Tsai, H.J., Tsai, A.C., Nriagu, J., Ghosh, D., Gong, M., Sandretto, A., 2006. Risk factors for respiratory symptoms and asthma in the residential environment of 5 th grade schoolchildren in Taipei, Taiwan. J. Asthma 43, 355-361. 
Vally, H., Thompson, P.J., 2002. Alcoholic drinks and asthma. Clin. Exp. Allergy 32, 186-191.

Van Duren-Schmidt, K., Pichler, J., Ebner, C., Bartmann, P., Forster, E., Urbanek, R., et al., 1997. Prenatal contact with inhalant allergens. Pediatr. Res. 41, 128-131.

Venables, K.M., Allitt, U., Collier, C.G., Emberlin, J., Greig, J.B., Hardaker, P.J., et al., 1997. Thunderstorm-related asthma - the epidemic of 24/25 June 1994. Clin. Exp. Allergy 27, 725-736.

Venn, A., Lewis, S., Cooper, M., Hill, J., Britton, J., 1998. Questionnaire study of effect of sex and age on the prevalence of wheeze and asthma in adolescence. Br Med. J. 316, 1945-1946.

von Mutius, E., 1998. The rising trends in asthma and allergic disease. Clin. Exp. Allergy 28 (Suppl. 5), 45-49 discussion 50-1.

von Mutius, E., Fritzsch, C., Weiland, S.K., Roll, G., Magnussen, H., 1992. Prevalence of asthma and allergic disorders among children in united Germany: a descriptive comparison. Br. Med. J. 305, 1395-1399.

von Mutius, E., Martinez, F.D., Fritzsch, C., Nicolai, T., Roell, G., Thiemann, H.H., 1994. Prevalence of asthma and atopy in two areas of West and East Germany. Am. J. Respir. Crit. Care Med. 149, $358-364$.
Wang, T.N., Ko, Y.C., Chao, Y.Y., Huang, C.C., Lin, R.S., 1999. Association between indoor and outdoor air pollution and adolescent asthma from 1995 to 1996 in Taiwan. Environ. Res. 81, 239-247.

Wardlaw, A.J., 1993. The role of air pollution in asthma. Clin. Exp. Allergy 23, 81-96.

Weiss, S.T., 1998. Environmental risk factors in childhood asthma. Clin. Exp. Allergy 28 (Suppl. 5), 29-34 discussion 50-1.

Whittemore, A.S., Korn, E.L., 1980. Asthma and air pollution in the Los Angeles area. Am. J. Public Health 70, 687-696.

Wilson, A.M., Wake, C.P., Kelly, T., Salloway, J.C., 2005. Air pollution, weather, and respiratory emergency room visits in two northern New England cities: an ecological time-series study. Environ. Res. 97, 312-321.

Wong, G.W., Lai, C.K., 2004. Outdoor air pollution and asthma. Curr. Opin. Pulm. Med. 10, 62-66.

Yunginger, J.W., Reed, C.E., O'Connell, E.J., Melton Jr., L.J., O’Fallon, W.M., Silverstein, M.D., 1992. A community-based study of the epidemiology of asthma. Incidence rates, 1964-1983. Am. Rev. Respir. Dis. $146,888-894$.

Zimmerman, B., Chambers, C., Forsyth, S., 1988. Allergy in asthma. II. The highly atopic infant and chronic asthma. J. Allergy Clin. Immunol. 81, 71-77. 